EXPERIMENTAL STUDY

\title{
Intralipid/heparin infusion suppresses serum leptin in humans
}

\author{
P García-Lorda, Wendy Nash, Ansley Roche, F-X Pi-Sunyer and B Laferrère \\ Obesity Research Center, St Luke's/Roosevelt Hospital Center, Columbia University College of Physicians and Surgeons, 1111 Amsterdam Avenue, \\ New York, NY 10025, USA \\ (Correspondence should be addressed to B Laferrère; Email: BBL14@columbia.edu)
}

\begin{abstract}
Background/aim: Our previous studies showed that administration of dexamethasone plus food increased serum leptin levels $100 \%$ more than dexamethasone alone. We hypothesized that this increase in leptin from the meal could result directly from the provision of fuel metabolites rather than from the meal-induced rise in insulin. In the current study, we tested the effect of an i.v. lipid fuel source (Intralipid 20\%/heparin) that would incur only a modest increase in insulin. This study was undertaken because the role of lipid in the regulation of human leptin levels has been controversial, with differing effects reported: stimulatory, inhibitory, or no effect at all.

Methods: In order to evaluate how lipids affect serum leptin in humans, we administered the following to seven lean, healthy, fasting subjects: (i) Intralipid $20 \%$ at $0.83 \mathrm{ml} / \mathrm{kg} . \mathrm{h}$ plus heparin (800 IE/h) infused i.v. for $7 \mathrm{~h}$ (LIPID), (ii) LIPID with one initial pulse of insulin $(0.09 \mathrm{U} / \mathrm{kg}$ ) given s.c. (LIPID+ INS), (iii) LIPID with dexamethasone $(2 \mathrm{mg}$ i.v. push) given at the start of the infusion (LIPID+DEX), and (iv) LIPID with insulin plus dexamethasone (LIPID+INS+DEX). Control trials in another 14 subjects matched hormonal conditions but lacked the LIPID infusion. Blood levels were collected over $8 \mathrm{~h}$ for determination of free fatty acids (FFA), glucose, insulin, and leptin under each experimental condition.

Results: Over the $420 \mathrm{~min}$ of LIPID infusion, FFA levels rose four-fold from $0.28 \pm 0.05 \mathrm{mmol} / \mathrm{l}$ to $0.99 \pm 0.05 \mathrm{mmol} / \mathrm{l}$. Serum leptin levels were suppressed by $10-20 \%$ in the LIPID condition as compared with control (no LIPID) between $90 \mathrm{~min}(P=0.008)$ and $360 \mathrm{~min}(P=0.045)$. LIPID+DEX did not increase leptin. A pulse of insulin (INS) increased serum insulin levels to $49.9 \pm 6.1 \mathrm{U} / \mathrm{ml}$ at $90 \mathrm{~min}$ and increased serum leptin by $21.3 \pm 6.6 \%$ at $480 \mathrm{~min}(P=0.054)$. LIPID decreased leptin in the face of this insulin-induced increase (LIPID+INS), between $360 \mathrm{~min}(P=0.017)$ and $420 \mathrm{~min}(P=0.003)$, with a $23 \%$ suppressive effect at $420 \mathrm{~min}$. LIPID+DEX elevated leptin levels by $112.5 \pm 35.8 \%$ at $480 \mathrm{~min}(P=0.037)$, however, the Intralipid/heparin infusion did not blunt the rise of leptin under these conditions.

Conclusions: These data showed that Intralipid/heparin: (i) are not sufficient to trigger the effect of dexamethasone on leptin, (ii) have an acute inhibitory effect on both fasting and insulin-stimulated leptin levels, and (iii) that this inhibitory effect cannot reverse the strong stimulatory effect of dexamethasone and insulin on serum leptin.
\end{abstract}

European Journal of Endocrinology 148 669-676

\section{Introduction}

Leptin levels are closely related to body fat mass (1). However, during fasting, leptin levels rapidly decrease without a change in fat mass (2), indicating that other factors, either hormonal, like insulin (3) and glucocorticoids (4), or metabolic, like glucose (5), play a role in rapid changes of leptin levels. While changes in free fatty acid (FFA) levels with lipid administration could also modulate leptin (by modifying insulin sensitivity and/or fat deposition and fat utilization) the effect of lipid administration on leptin has been controversial.
In vitro, palmitate and/or 2-bromopalmitate downregulate leptin secretion from rat adipocytes (6), whereas in vivo, lipid infusion increases leptin mRNA expression and levels in rodents (7). In humans, conditions known to inhibit leptin gene expression such as starvation (8) or cold exposure (9), are associated with increased lipolysis and elevated FFA or glycerol levels. Similarly, in vivo isoproterenol infusion $(10,11)$ or in vitro treatment of human adipocytes with isoproterenol (12) decreases leptin levels. A positive correlation has been shown between fasting serum leptin and FFA levels in women (13). Similarly, in normally fed lean and obese adolescents, a positive correlation between nocturnal 
peak plasma FFA and leptin has been shown (14). On the contrary, others have reported an inverse correlation between serum leptin and FFA levels in lean subjects during an extended $26 \mathrm{~h}$ fast (15).

Nonetheless, most studies in humans have failed to show a direct effect of lipid infusion on leptin. Infusing Intralipid $10 \%(16,17)$ or $20 \%(18,22)$ without $(17)$ or with $(16,18,22)$ heparin to increase levels of FFA, or blocking FFA release by acipimox, the nicotinic acid analog $(16,18-20)$, did not change leptin levels. Most studies however, have reported the effect of Intralipid/heparin infusion under fasting conditions (18), and not under fed conditions (i.e. in the presence of elevated glucose and insulin). Two studies have shown a small stimulatory effect of in vivo Intralipid $10 \% /$ heparin on serum leptin during a hyperglycemic clamp (21), and of Intralipid 20\%/heparin on leptin mRNA in gluteal subcutaneous fat but not on plasma leptin levels in lean subjects (22). One study reported an inhibitory effect on leptin at $6 \mathrm{~h}$ when the same amount of fat was given either as an oral load or as an Intralipid infusion (23).

In summary, clinical studies of the effect of lipid administration on leptin have yielded inconsistent results. In order to evaluate further the role of circulating FFA as a potential modulator of leptin levels in human subjects, we examined the effect of an Intrali$\mathrm{pid} /$ heparin infusion on leptin. Intralipid is a $20 \%$ triglyceride emulsion. The addition of heparin to the Intralipid infusion releases lipoprotein lipase into the bloodstream, thus facilitating the breakdown of circulating triglycerides and increasing circulating FFA. This current study was designed to evaluate whether:
1) Intralipid/heparin, administered as the only fuel, could increase leptin levels in the absence and/or in the presence of dexamethasone; and 2) Intralipid/heparin could act synergistically with insulin and glucose to raise leptin levels in the presence of dexamethasone.

\section{Subjects and methods}

\section{Subjects}

Nineteen healthy subjects (17 male, two female) aged $25 \pm 6$ years, with body mass index (BMI) of $25 \pm$ $3 \mathrm{~kg} / \mathrm{m}^{2}$ were studied (Table 1). All were non-smokers and weight-stable during the previous 3 months, and none were taking medication at the time of the study. All subjects displayed normal results for routine blood tests, thyroid function and oral glucose tolerance tests. Total body fat was measured by dual X-ray absorptiometry. Female subjects were studied in the follicular phase of the menstrual cycle. The study protocol was approved by the Institutional Review Board of St Luke's/Roosevelt Hospital, and fully-informed written consent was obtained from each participant.

\section{Experiments}

Experimental design Subjects reported to the Clinical Research Center at $0745 \mathrm{~h}$ after an overnight fast. An i.v. catheter was inserted into an antecubital vein and the i.v. line was kept open with a slow infusion of $0.45 \%$ sodium chloride during the entire experiment. This line was used for blood sampling. Under some study conditions, another i.v. catheter was inserted in

Table 1 Subject characteristics.

\begin{tabular}{|c|c|c|c|c|c|c|c|c|}
\hline Subject & Gender & Experiment & $\begin{array}{c}\text { Age } \\
\text { (years) }\end{array}$ & $\begin{array}{c}\text { BMI } \\
\left(\mathrm{kg} / \mathrm{m}^{2}\right)\end{array}$ & $\begin{array}{c}\text { Fat mass } \\
(\%)\end{array}$ & $\begin{array}{c}\text { Glucose } \\
(\mathrm{mmol} / \mathrm{l})\end{array}$ & $\begin{array}{l}\text { Insulin } \\
\text { (pmol//) }\end{array}$ & $\begin{array}{l}\text { Leptin } \\
(\mathrm{ng} / \mathrm{ml})\end{array}$ \\
\hline 1 & $M$ & INTRALIPID & 31 & 23.6 & 14 & 5.3 & 72 & 3.2 \\
\hline 2 & M & INTRALIPID/CONTROL 2 & 27 & 23.8 & 21 & 5.5 & 76 & 6.3 \\
\hline 3 & M & INTRALIPID/CONTROL 2 & 19 & 25.1 & 13 & 5.0 & 39 & 2.4 \\
\hline 4 & M & INTRALIPID & 22 & 23.0 & 19 & 5.4 & 68 & 3.4 \\
\hline 5 & $\mathrm{~F}$ & INTRALIPID & 22 & 22.5 & 30 & 4.4 & 80 & 13.2 \\
\hline 6 & M & INTRALIPID & 19 & 25.2 & 15 & 4.9 & 42 & 1.7 \\
\hline 7 & M & INTRALIPID & 21 & 22.8 & 16 & 5.1 & 48 & 1.9 \\
\hline 8 & $M$ & CONTROL 2 & 26 & 22.3 & 19 & 4.8 & 63 & 3.2 \\
\hline 9 & M & CONTROL 2 & 19 & 24.7 & 15 & 5.2 & 65 & 1.2 \\
\hline 10 & $M$ & CONTROL 2 & 24 & 25.2 & 11 & 5.4 & 58 & 5.4 \\
\hline 11 & $\mathrm{~F}$ & CONTROL 2 & 18 & 20.2 & 26 & 5.2 & 81 & 6.7 \\
\hline 12 & $M$ & CONTROL 1 & 25 & 27.5 & 21 & 5.1 & 98 & 2.9 \\
\hline 13 & M & CONTROL 1 & 30 & 26.2 & 29 & 5.5 & 42 & 4.5 \\
\hline 14 & $M$ & CONTROL 1 & 24 & 27 & 18 & 5.2 & 71 & 3.2 \\
\hline 15 & $M$ & CONTROL 1 & 26 & 32.3 & 31 & 6.1 & 151 & 6.6 \\
\hline 16 & $M$ & CONTROL 1 & 43 & 26.7 & 38 & 4.8 & 115 & 11.7 \\
\hline 17 & M & CONTROL 1 & 24 & 24.6 & 25 & 5 & 57 & 4.7 \\
\hline 18 & M & CONTROL 1 & 28 & 25.2 & 19 & 4.7 & 67 & 4.6 \\
\hline 19 & $M$ & CONTROL 1 & 26 & 22.5 & 21 & 5 & 77 & 2.6 \\
\hline Means \pm S.D. & & & $25 \pm 6$ & $24.9 \pm 2.8$ & $21.4 \pm 7.2$ & $5.1 \pm 0.4$ & $72 \pm 27$ & $4.7 \pm 3.2$ \\
\hline
\end{tabular}

$M$, male; $F$, female. 
an antecubital vein of the contralateral arm for administration of $20 \%$ glucose and/or for Intralipid infusion via a peristaltic pump (Gemini PC-1, Imed, San Diego CA, USA). Intralipid 20\% (Fresenius Kabi, Clayton NY, USA) is a commercial emulsion of soybean oil. Blood samples were collected every $30 \mathrm{~min}$ over the next $8 \mathrm{~h}$ for assay of serum leptin, C-peptide, insulin and FFA.

Experimental protocol: Intralipid/heparin infusion (INTRALIPID) The effect of the i.v. administration of Intralipid $20 \%$ at $0.83 \mathrm{ml} / \mathrm{kg}$.h and heparin $(800$ IE/h, priming dose $1000 \mathrm{IE})$ for $7 \mathrm{~h}$ was studied in seven subjects under four different conditions: 1) Intralipid/heparin alone (LIPID), 2) Intralipid/heparin infusion with an additional pulse of insulin (Humalog, Eli Lilly, Indianapolis, USA, at $0.09 \mathrm{U} / \mathrm{kg}$ ) administered s.c. at the start of the lipid infusion (LIPID+INS), 3) Intralipid/heparin infusion with dexamethasone $(2 \mathrm{mg}$ i.v. over $1 \mathrm{~min}$ ) given at the start of the lipid infusion (LIPID+DEX), and 4) Intralipid/heparin with insulin and dexamethasone at the above mentioned doses $(\mathrm{LIPID}+\mathrm{INS}+\mathrm{DEX})$. For conditions where insulin was administered, a 20\% glucose infusion was adjusted by a peristaltic pump to maintain baseline blood glucose levels throughout the entire experiment. The order of the four conditions was assigned by means of a Latin square, and each condition was separated by 1 to 4 weeks.

Control Experiment 1: Fasting with and without dexamethasone (CONTROL 1) Eight male subjects were studied under two conditions: complete fast $(8 \mathrm{~h}$ fast after an overnight fast and saline infusion (FAST) and complete fast plus dexamethasone (2 mg i.v.), administered after baseline measurements were taken (DEX).

Control Experiment 2: Insulin with or without dexamethasone (CONTROL 2) After basal measurements, seven subjects $(n=7$, six male, one female) received a s.c. pulse of short acting insulin (Humalog, Lilly) at a dose of $0.09 \mathrm{U} / \mathrm{kg}$. Subjects simultaneously received either $2 \mathrm{mg}$ of dexamethasone (INS+DEX) or saline (INS) administered as an i.v. push at $0830 \mathrm{~h}$. Blood glucose was determined at intervals of $5 \mathrm{~min}$ and the glucose level was maintained at baseline levels by varying the rate of the $20 \%$ glucose infusion. The order of the two conditions was assigned with the INS+DEX run first in order to match the slight hyperglycemic effect of dexamethasone during the INS condition.

For all eight experimental conditions, the subjects received no oral food intake (were fasted). However, the terminology FAST refers to the fasting condition with neither hormonal nor fuel challenge. Two subjects participated in both INTRALIPID and CONTROL 2 experiments.

\section{Analytical methods}

Assays Serum glucose was measured with a glucose analyzer (Beckman). Plasma insulin and leptin (kits from Linco, St Charles, MO, USA) and C-peptide (DPC, Los Angeles, CA, USA) were determined by radioimmunoassay. FFAs were measured by an enzymatic method (Wako Chemicals USA, Inc., Richmond, VA, USA). All plasma samples were run in duplicate and all data for each subject were analyzed simultaneously. The interassay coefficient of variation (CV) for leptin was $8.4 \%$ and $5.2 \%$ and the intra-assay $7.2 \%$ and $5.3 \%$ for a level of $2.8 \mathrm{ng} / \mathrm{ml}$ and $20.3 \mathrm{ng} / \mathrm{ml}$ respectively. The interassay $\mathrm{CV}$ for insulin was $8.5 \%$ and $6.9 \%$ and the intra-assay $6.2 \%$ and $5.2 \%$ for levels of $10.4 \mu \mathrm{U} / \mathrm{ml}$ and $45 \mu \mathrm{U} / \mathrm{ml}$ respectively.

\section{Statistical analysis}

The response variables are the levels at every time point, and the area under the curve (AUC) (24) for glucose, leptin, C-peptide, insulin and FFA. The relative change in leptin at $8 \mathrm{~h}$ was defined as: (leptin at $480 \mathrm{~min}$ [PGL1] - leptin at $0 \mathrm{~min}) /($ leptin at $0 \mathrm{~min}) \times 100$. General linear model analysis with repeated measures was performed separately for each condition of the three experiments to evaluate the change of leptin from baseline. ANOVA followed by Bonferroni post hoc analysis was performed to compare conditions within the same experiment. ANOVA was used to compare a variable between two conditions between two experiments. Because two subjects were both in the LIPID and the CONTROL 2 groups, the analyses were re-run with each of these two subjects participating in one group exclusively, without changes in the significance of the results. All data are presented as means \pm S.E.M. unless otherwise specified. The data were analyzed using SPSS for PC (Software Version 10, SPSS Inc., Chicago, IL, USA). $P<0.05$ was considered significant.

\section{Results}

Subject characteristics are shown in Table 1. There was no difference in BMI, glucose or insulin levels between groups of subjects. Serum FFA levels were identical during the four conditions involving Intralipid infusion, either at baseline or during the infusion (Fig. 1). During the Intralipid/heparin infusion, serum FFA levels rose by a factor of four from $0.28 \pm 0.05 \mathrm{mmol} / \mathrm{l}$ to $0.99 \pm 0.05 \mathrm{mmol} / \mathrm{l} 420 \mathrm{~min}$ into the infusion.

\section{Intralipid/heparin infusion (LIPID) enhances the decline of leptin with fasting (Fig. 2A)}

Leptin levels declined over time with FAST, with a $23.6 \pm 5.7 \%$ reduction at $480 \mathrm{~min}(P=0.032)$. Leptin similarly decreased during LIPID, with a $28.9 \pm 1.4 \%$ decline at $480 \mathrm{~min}(P=0.045)$. However, during 

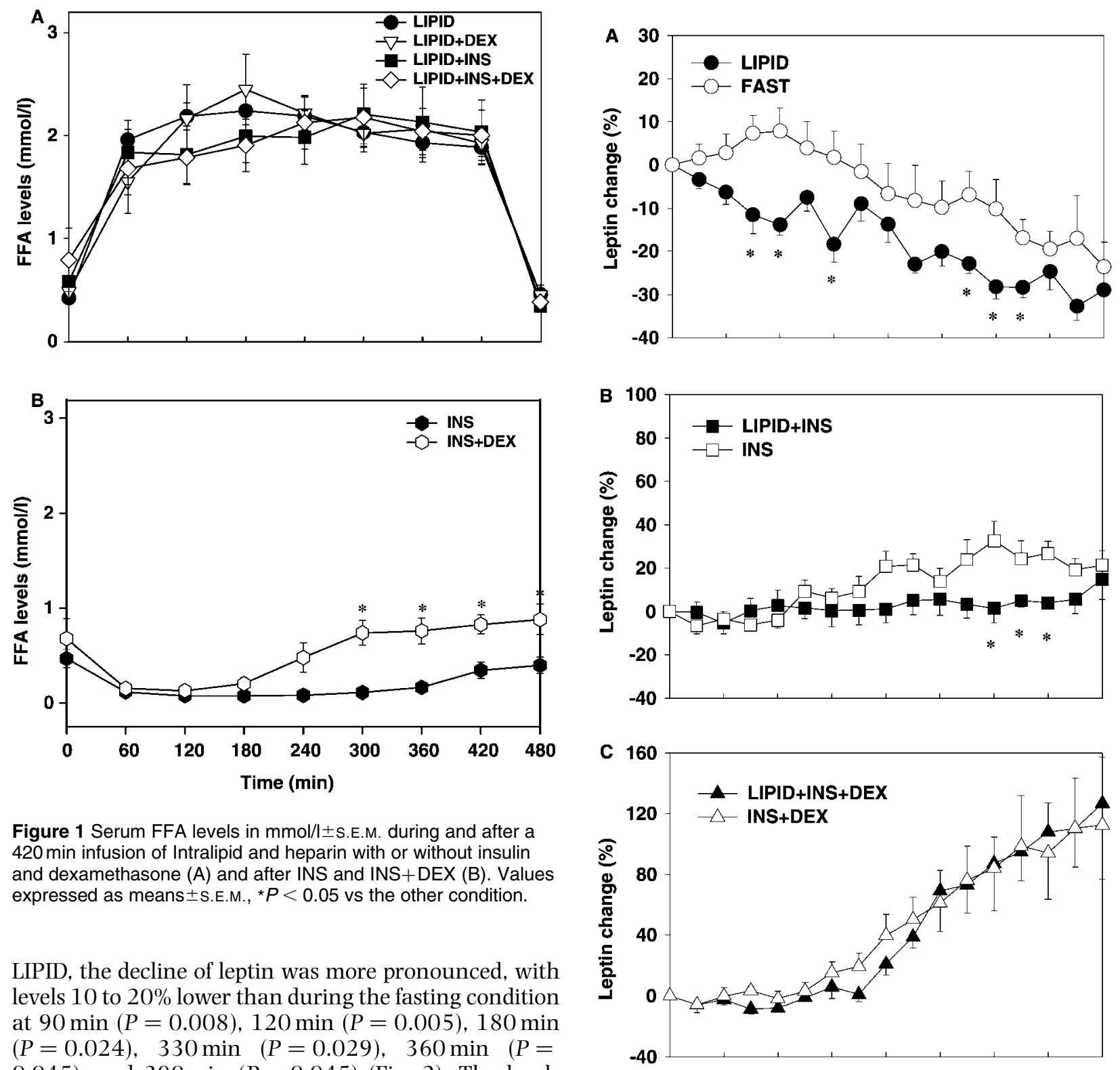

Figure 1 Serum FFA levels in $\mathrm{mmol} / \mathrm{I} \pm$ S.E.M. during and after a 420 min infusion of Intralipid and heparin with or without insulin and dexamethasone (A) and after INS and INS+DEX (B). Values expressed as means \pm S.E.M., ${ }^{\star} P<0.05$ vs the other condition.

LIPID, the decline of leptin was more pronounced, with levels 10 to $20 \%$ lower than during the fasting condition at $90 \mathrm{~min}(P=0.008), 120 \mathrm{~min}(P=0.005), 180 \mathrm{~min}$ $(P=0.024), \quad 330 \mathrm{~min} \quad(P=0.029), 360 \mathrm{~min} \quad(P=$ $0.045)$, and $390 \mathrm{~min}(P=0.045)$ (Fig. 2). The levels were not different between the FAST and LIPID conditions at $480 \mathrm{~min}$, a time at which the Intralipid/ heparin had been discontinued for $1 \mathrm{~h}$. There was no difference in glucose levels between FAST and LIPID. Insulin levels decreased with FAST by $-42 \%$ at $480 \mathrm{~min}$. Insulin levels decreased during LIPID by $-27 \%$ at $480 \mathrm{~min}$. Insulin levels were higher during LIPID than during FAST at $150 \mathrm{~min}(P=0.04)$, $210 \mathrm{~min}(P=0.006), 270 \mathrm{~min}(P=0.036)$, and from

Figure 2 Serum leptin levels, expressed as the percentage change from baseline. Comparison of FAST and LIPID (A), INS and LIPID+INS (B), INS+DEX and INS+DEX+LIPID (C), LIPID+DEX and DEX (panel D). Values expressed as means \pm S.E.M., ${ }^{*} P<0.05$ vs the other condition.

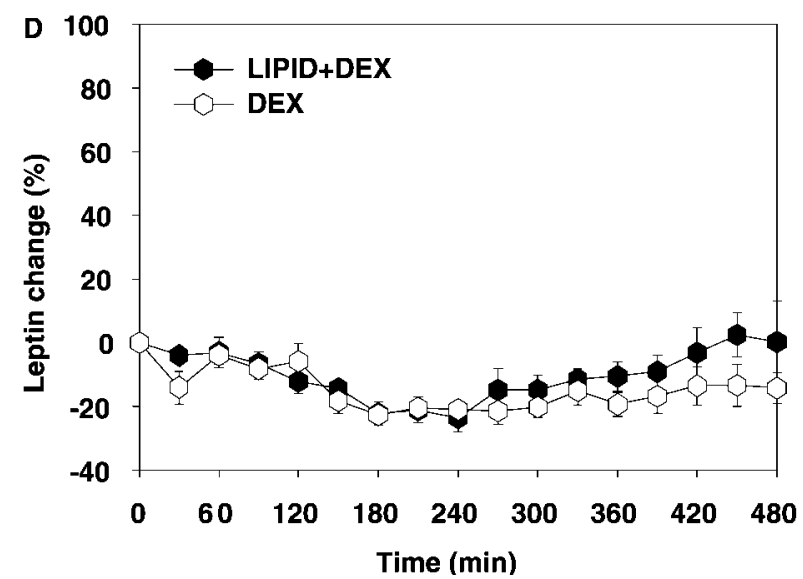


$330 \mathrm{~min}$ to $450 \mathrm{~min}$ (ANOVA $\mathrm{P}<0.04$ at each time points) (Fig. 3).

\section{LIPID decreases leptin in the face of an insulin-induced increase (Fig. 2B)}

The administration of a s.c. pulse of insulin (INS) induced a significant increase of serum insulin levels to $350 \pm 42 \mathrm{pmol} / \mathrm{l}$ at $90 \mathrm{~min}$. Serum leptin levels rose significantly $(P<0.001)$, starting at $270 \mathrm{~min}$ $(P=0.032)$, with a $21.3 \pm 6.6 \%$ increase at $480 \mathrm{~min}$ $(P=0.054)$. When LIPID was co-administered with the insulin pulse (LIPID+INS), the stimulatory effect of insulin disappeared. Although leptin levels did not significantly change from baseline at any time point, serum leptin was about $23 \%$ lower between $360 \mathrm{~min}$ $(P=0.017)$ and $420 \mathrm{~min}(P=0.003)$ in LIPID+INS as compared with INS. No difference was seen at $480 \mathrm{~min}, 1 \mathrm{~h}$ after LIPID infusion was discontinued. Insulin, C-peptide and glucose were not significantly different between the two conditions. FFA levels were significantly higher in the LIPID+INS condition as compared with the INS condition (FFA AUC 220.3 \pm $32.4 \mathrm{mmol} / \mathrm{l} / 420 \mathrm{~min}$ vs $23.55 \pm 4.4 \mathrm{mmol} / \mathrm{l} / 420 \mathrm{~min}$, $\mathrm{P}<0.001)$.

The total amount of glucose administered during the experiment, used as an indicator of total body insulin sensitivity, was significantly lower during LIPID+INS compared with INS alone $(115 \pm 43 \mathrm{~g} / 8 \mathrm{~h}$ vs $184.6 \pm 50.8 \mathrm{~g} / 8 \mathrm{~h}, P=0.017)$.

\section{LIPID does not blunt the rise in leptin with INS + DEX}

The amplitude and pattern of decline of leptin after dexamethasone administration (DEX) $(-14.2 \pm 4.8 \%$, $P=0.026)$ was similar to that observed during fasting (FAST) (see Fig. 2A). The decline of leptin was not different with LIPID+DEX or with LIPID alone.

As we have shown previously (25), INS+DEX produced a significant increase in leptin levels above baseline $(P<0.001)$, starting at $240 \mathrm{~min}(P=0.038)$ and increasing by $112.5 \pm 35.8 \%$ at $480 \mathrm{~min}(P=0.037)$. Simultaneous infusion of Intralipid (LIPID+ INS+DEX) had no effect on this increase (Fig. 2C). There were also no differences in insulin, C-peptide, glucose levels and glucose infusion rates between both conditions, but the concentration of FFA was significantly higher in the intralipid infusion condition (FFA AUC 217.7 \pm $28.5 \mathrm{mml} / \mathrm{l} / 420 \mathrm{~min}$ vs $71.6 \pm 12.8 \mathrm{~mm} / \mathrm{l} / 420 \mathrm{~min}$, $P=0.001)$.

Figure 3 Serum insulin levels, expressed as the percentage change from baseline. Comparison of FAST and LIPID (A), INS and LIPID+INS (B), INS+DEX and INS+DEX+LIPID (C), LIPID+DEX and DEX (D). Values expressed as means \pm S.E.M., ${ }^{\star} P<0.05$ vs the other condition.
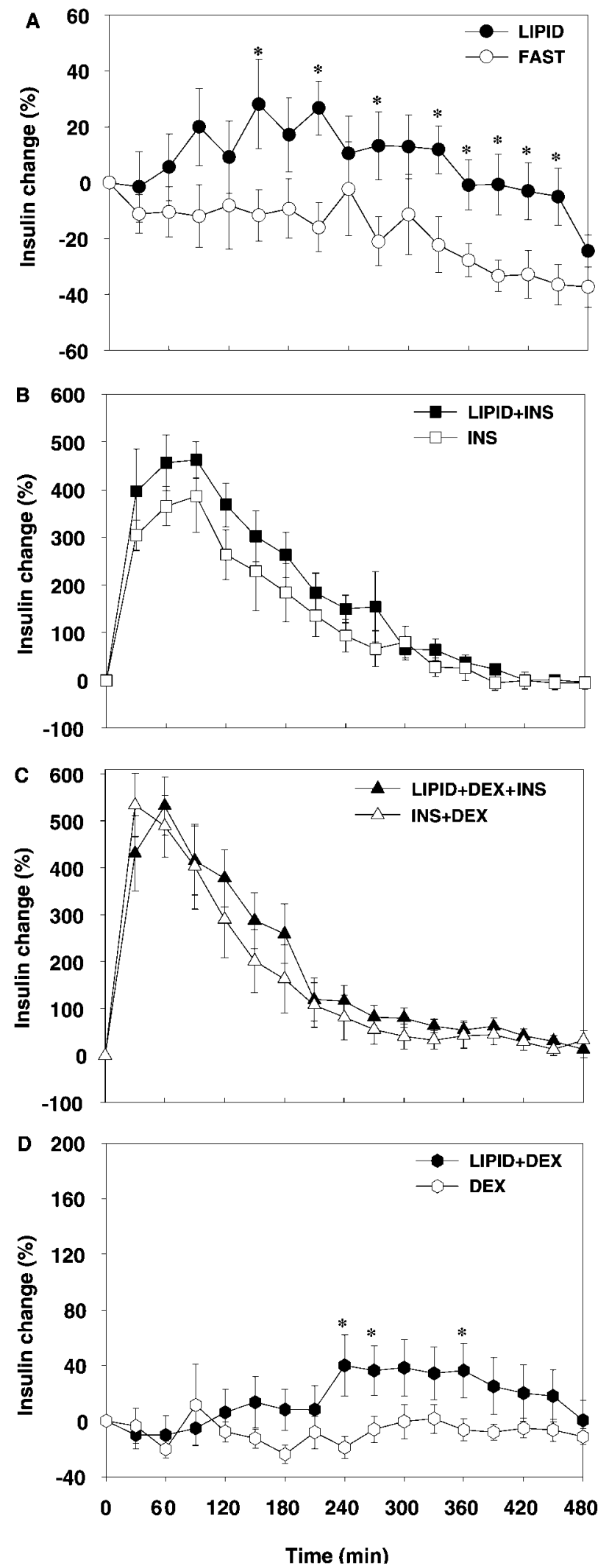

www.eje.org 


\section{Discussion}

In order to investigate the role of FFA in the regulation of leptin levels, the effect of an Intralipid 20\%/heparin infusion was studied in the presence or absence of insulin and/or dexamethasone. A four-fold increase of serum FFA levels from baseline after the LIPID infusion did not result in an increase of leptin levels, regardless of the presence or absence of insulin and/or dexamethasone. This observation strongly suggests the absence of any stimulatory effect of infused lipids (FFA) on leptin under our experimental conditions. We cannot rule out, however, a possible stimulatory effect of lipid infusion on leptin gene expression, in the absence of a measurable effect on leptin serum levels, as shown by others (22). Our finding is contrary to the study by Stefan et al. (21), which showed a small stimulatory effect of Intralipid 10\%/heparin. These discrepancies may be explained by different experimental conditions as Stefan et al. used the co-administration of a hyperglycemic clamp (21), while we used a single pulse of insulin and euglycemia, and by the composition of the Intralipid emulsion that were used, the $10 \%$ Intralipid emulsion having a higher phospholipid: triglyceride ratio than the $20 \%$ Intralipid emulsion that we used.

In our previous studies, we showed that dexamethasone requires either food intake ( $2000 \mathrm{kcal})(4)$ or insulin and glucose (about $800 \mathrm{kcal}$ over an $8 \mathrm{~h}$ period) (25) to demonstrate its stimulatory effect on leptin. In the present study, however, the increase in FFA secondary to the Intralipid/heparin infusion (about $700 \mathrm{kcal}$ over a $7 \mathrm{~h}$ period) cannot trigger the dexamethasone effect on leptin. It is therefore not fuel availability but the type of nutrient available (i.e. glucose) and/or the presence of insulin that triggers the effect of dexamethasone on leptin. Others have also proposed that it is not so much the provision of energy, but the presence of insulin-stimulated glucose metabolism that is critical for elevating leptin secretion $(23,26)$.

On the contrary, this study shows that i.v. triglycerides have a modest but significant suppressive effect on leptin serum levels, when administered as an emulsion of Intralipid with heparin. The lipid (about $80 \mathrm{~g}$ of total lipid administered over a $7 \mathrm{~h}$ period, depending on the body weight of the subjects) suppressed leptin levels during the time of the infusion by $10-20 \%$, as compared with the control FAST condition. The effect appeared $90 \mathrm{~min}$ after the start of the infusion and lasted for the duration of the infusion. The mechanism of this inhibition is unclear. The relative state of insulin resistance, demonstrated by higher insulin levels during LIPID, could play a role.

This is in concordance with the in vivo study of Evans et al., showing an inhibitory effect of a $40 \mathrm{~g}$ fat load administered as Intralipid either orally or i.v. (with heparin) in human subjects (23). This is also in concordance with previous in vitro data showing inhibition of $o b$ gene expression by the fatty acid bromopalmitate in a 3T3-L1 cell line (27), a dose-dependent suppressive effect of oleic acid in cultured murine adipocytes (28), and a decrease in leptin accumulation by palmitate and 2-bromopalmitate in the culture medium of rat adipocytes (6). Although smaller, the level of FFA achieved during the infusion was comparable to that observed by others after epinephrine infusion (11), a situation in which leptin is also suppressed. It is unclear why the suppressive effect of lipid infusion on leptin was not found by other in vivo studies in humans. One study involved similar infusion time, type of Intralipid emulsion $(20 \%)$ and serum FFA level increases (five-fold) after Intralipid/heparin, but found no inhibitory effect (18). Other studies used shorter infusion time and different composition of Intralipid emulsion (10\% instead of $20 \%$ ), which could possibly explain the absence of an inhibitory effect (16).

A second finding of our study is that this suppressive effect of FFA on leptin is also apparent in a situation where leptin is stimulated by a pulse of insulin. In that situation, the effect appeared $240 \mathrm{~min}$ after the start of the infusion and lasted for the duration of the infusion, disappearing $1 \mathrm{~h}$ after discontinuation. Fatty acids decrease glucose utilization in humans (29) and insulin resistance develops as a result of the greater FFA availability driven by Intralipid plus heparin infusion (7). In our experiment, LIPID did induce a relative state of insulin resistance, with less glucose infused to maintain glucose levels in the LIPID+INS as compared with the INS condition. The state of insulin resistance could impinge on the ability of insulin and glucose to stimulate leptin. The result of our LIPID+ INS experiment, however, contradicts an in vivo study showing a stimulation of leptin after a hyperglycemic clamp and a 24-h Intralipid infusion (21). However, it is very possible that the higher levels of glucose and the longer period of insulin and Intralipid infusion in their experiment $(24 \mathrm{~h})$, as opposed to a single pulse of s.c. insulin in our experiment, were responsible for the leptin stimulation.

Finally, when leptin was optimally stimulated by INS+DEX, the suppressive effect of FFA was not apparent. The FFA effect appears to be overriden by the stimulatory effect of INS+DEX on leptin. This shows that in a situation with a lesser degree of insulin sensitivity, in the presence of glucocorticoid administration $(30,31)$ and FFA infusion (7), leptin levels can be stimulated.

Some have shown that a 4-h Intralipid infusion, without heparin, induced an inhibition of adipose tissue lipolysis and a 35\% decrease, albeit not statistically significant, of leptin levels (17). Although we did not measure the rate of lipogenesis or lipolysis, it is possible to speculate that the change in FFA levels secondary to the LIPID infusion regulate, together with the rates of lipogenesis and lipolysis, the rate of leptin secretion. 
Because an infusion of triglycerides is not the same as oral fat intake, it is unclear whether these data are applicable to a physiological food intake situation. However, our results compare well with those of Evans et al. (23) who used a smaller i.v. load, equivalent to what he gave during an oral fatty meal. Future research needs to focus on the impact of oral fat intake and the composition of the fat, together with rates of whole body and depot-specific lipogenesis/ lipolysis, on leptin expression and secretion.

In summary, our data show that: 1) Intralipid/heparin does not increase leptin levels in the absence or presence of dexamethasone; 2) in vivo administration of Intralipid/heparin has an acute inhibitory effect on leptin in human subjects that may be due, in part, to a decrease of insulin sensitivity; and 3) the inhibitory effect of Intralipid/heparin is small and cannot reverse the strong stimulatory effect of dexamethasone and insulin on serum leptin.

\section{Acknowledgements}

This work was supported by a grant from the American Diabetes Association, and by NIH grants K08 DK 02572-01, M01RR00645, and DK-26687. Pilar García-Lorda was supported by the Human Nutrition Unit, Faculty of Medicine and Health Sciences, Universitat Rovira i Virgili, Reus, Spain. We are grateful to Colleen Russel and Jeanine Albu for their comments on the manuscript.

\section{References}

1 Lönnqvist F, Nordfors L, Jansson M, Thorne A, Schalling M \& Arner P. Leptin secretion from adipose tissue in women. Relationship to plasma levels and gene expression. Journal of Clinical Investigation $1997992398-2404$.

2 Boden G, Chen X, Mozzoli M \& Ryan I. Effect of fasting on serum leptin in normal subjects. Journal of Clinical Endocrinology and Metabolism 199681 3419-3423.

3 Saad MF, Khan A, Sharma A, Michael R, Riad-Gabriel M, Boyadjian R et al. 1998 Physiological Insulinemia acutely modulates plasma leptin. Diabetes $199847544-549$.

4 Laferrère B, Fried SK, Hough K, Campbell SA, Thornton J \& Pi-Sunyer FX. Synergistic effects of feeding and dexamethasone on serum leptin levels. Journal of Clinical Endocrinology and Metabolism $1998 \mathbf{8 3} 3742-3745$.

5 Havel PJ, Townsend R, Chaump L \& Teff K. High-fat meals reduce 24-h circulating leptin concentrations in women. Diabetes 1999 48 334-341.

6 Shintani M, Nishimura H, Yonemitsu S, Masuzaki H, Ogawa Y, Hosoda $\mathrm{K}$ et al. Downregulation of leptin by free fatty acids in rat adipocytes: effects of triacsin $\mathrm{C}$, palmitate, and 2-bromopalmitate. Metabolism 200049 326-330.

7 Fabris R, Nisoli E, Lombardi AM, Tonello C, Serra R, Granzotto M et al. Preferential channeling of energy fuels toward fat rather than muscle during high free fatty acid availability in rats. Diabetes $2000 \mathbf{5 0} 601-608$.

8 Dubuc GR, Phinney SD, Stern JS \& Havel PJ. Changes in serum leptin and endocrine and metabolic parameters after 7 days of energy restriction in men and women. Metabolism $1998 \mathbf{4 7}$ 429-434.
9 Ricci MR, Fried SK \& Mittleman KD. Acute cold exposure decreases plasma leptin in women. Metabolism 200049 421-423.

10 Donahoo WT, Jensen DR, Yost TJ \& Eckel RH. Isoproterenol and somatostatin decrease plasma leptin in humans: a novel mechanism regulating leptin secretion. Journal of Clinical Endocrinology and Metabolism $1997 \mathbf{8 2} 4139-4143$.

11 Couillard C, Mauriège P, Prud'homme D, Nadeau A, Tremblay A, Bouchard $\mathrm{C}$ et al. Plasma leptin response to an epinephrine infusion in lean and obese women. Obesity Research 200210 6-13.

12 Ricci MR \& Fried SK. Isoproterenol decreases leptin expression in adipose tissue of obese humans. Obesity Research 19997 233-240.

13 Der Merwe MT, Panz VR, Crowther NJ, Schlaphoff GP, Gray IP, Froguel $\mathrm{P}$ et al. Free fatty acids and insulin levels- relationship to leptin levels and body composition in various patient groups from South Africa. International Journal of Obesity 199923 909-917.

14 Heptulla R, Smitten A, Teague B, Tamborlane WV, Ma Yong-Zhan \& Caprio S. Temporal patterns of circulating leptin levels in lean and obese adolescents: relationships to insulin, growth hormone, and free fatty acids rhythmicity. Journal of Clinical Endocrinology and Metabolism 200186 90-96.

15 Sonnenberg GF, Krakower GR, Hoffmann RG, Maas DL, Hennes MMI \& Kissebah AH. Plasma leptin concentrations during extended fasting and graded glucose infusions: relationships with changes in glucose, insulin, and FFA. Journal of Clinical Endocrinology and Metabolism 200186 4895-4900.

16 Peino R, Fernández Alvarez J, Peñalva A, Considine RV, Rodriguez-Segade S, Rodriguez-Garcia J et al. Acute changes in free-fatty acids (FFA) do not alter serum leptin levels. Journal of Endocrinological Investigation 199821 526-530.

17 Samra JS, Giles SL, Summers LKM, Evans RD, Arner P, Humphreys SM et al. Peripheral fat metabolism during infusion of an exogenous triacylglycerol emulsion. International Journal of Obesity $199822806-812$.

18 Stumvoll M, Fritsche A, Tschritter O, Lehmann R, Wahl HG, Renn W et al. Leptin levels in humans are acutely suppressed by isoproterenol despite acipimox-induced inhibition of lipolysis, but not by free fatty acids. Metabolism $200049335-339$.

19 Hennes MM, Dua A, Maas DL, Sonnenberg GE, Krakower GR \& Kissebah AH. Relationships of plasma leptin levels to changes in plasma free fatty acids in women who are lean and women who are abdominally obese. Obesity Research $1997 \mathbf{5}$ $442-446$.

20 Worm D, Vinten J, Vaag A, Henriksen JE \& Beck-Nielsen H. The nicotinic acid analogue acipimox increases plasma leptin and decreases free fatty acids in type 2 diabetic patients. European Journal of Endocrinology 2000143 389-395.

21 Stefan N, Fritsche A, Häring H \& Stumvoll M. Acute stimulation of leptin concentrations in humans during hyperglycemic hyperinsulinemia. Influence of free fatty acids and fasting. International Journal of Obesity $200125138-142$.

22 Nisoli E, Carruba MO, Tonello C, Macor C, Federspil G \& Vettor R. Induction of fatty acid translocase/CD36 peroxisome proliferatoractivated receptor- $\gamma 2$, leptin, uncoupling proteins 2 and 3 , and tumor necrosis factor- $\alpha$ gene expression in human subcutaneous fat by lipid infusion. Diabetes 200049 319-324.

23 Evans K, Clark ML \& Frayn N. Carbohydrate and fat have different effects on plasma leptin concentrations and adipose tissue leptin production. Clinical Science $2001 \mathbf{1 0 0} 493-498$.

24 Kaiser KS. Numerical Analysis, pp 146. New York: McGraw-Hill Book Company, 1957.

25 Laferrère B, Caixas A, Fried SK, Bashore C, Kim J \& Pi-Sunyer FX. A pulse of insulin and dexamethasone stimulates serum leptin in fasting human subjects. European Journal of Endocrinology 2002 $146839-845$.

26 Coleman RA \& Herman TS. Nutritional regulation of leptin in humans. Diabetologia 199942 639-646. 
27 Rentsch J \& Chiesi M. Regulation of ob gene mRNA levels in cultured adipocytes. FEBS Letters 1996379 55-59.

28 Deng C, Moinat M, Curtis L, Nakadal A, Preitner F, Boss O et al. Effects of beta-adrenoceptor subtype stimulation on obese gene messenger ribonucleic acid and on leptin secretion in mouse brown adipocytes differentiated in culture. Endocrinology 1997 $138548-552$.

29 Ferrannini E, Barret EJ, Bevilacqua S \& DeFronzo RA. Effect of fatty acids on glucose production and utilization in man. Journal of Clinical Investigation $1983 \mathbf{7 2} 1737-1747$.
30 Appel B \& Fried SK. Effects of insulin and dexamethasone on lipoprotein lipase in human adipose tissue. American Journal of Physiology 1992262 E695-E699.

31 Sakoda H, Ogihara T, Anai M, Funaki M, Inukai K, Katagiri H et al. Dexamethasone-induced insulin resistance in 3T3-L1 adipocytes is due to inhibition of glucose transport rather than insulin signal transduction. Diabetes 200049 1700-1708.

Received 9 December 2002

Accepted 17 March 2003 